Connotas. Revista de crítica y teoría literarias 
CONNOTAS. REVISTA DE CRÍTICA Y TEORÍA LITERARIAS. Enero - diciembre 2013, es una publicación anual editada por la Universidad de Sonora, a través de la División de Humanidades y Bellas Artes, en el Departamento de Letras y Lingüística. Blvd. Luis Encinas y Blvd. Rosales s/n, Col. Centro, C.P. 83000, Hermosillo Sonora; Tel. (662) 2592 136, (662) 2592 157, <www.uson.mx>, <http://www.connotas.uson.mx, connotas@capomo.uson.mx>. Editor responsable: Rosario Fortino Corral Rodríguez. Reservas de Derechos al Uso Exclusivo núm. 04-2006-020714184900-102. ISSN: 18706630; ambos otorgados por el Instituto Nacional del Derecho de Autor. Licitud de Título núm. 13434 y de Contenido núm. 11007, otorgados por la Comisión Calificadora de Publicaciones y Revistas Ilustradas de la Secretaría de Gobernación. Este libro se publicó con el apoyo del Programa Integral de Fortalecimiento Institucional C/PIFI 2013-12934

Se autoriza la reproducción total o parcial de los contenidos de la presente publicación, siempre y cuando se acredite adecuadamente el origen de los mismos.

Datos de contacto para la publicación: División de Humanidades y Bellas Artes, Departamento de Letras y Lingüística; Apartado Postal 793, Col. Centro, C.P. 83000, Hermosillo, Sonora, México. Tels.: (662) 259-21-87, Tel-fax 212-55-29. Correo electrónico: connotas@capomo.uson.mx Página web: http://www.connotas.uson.mx 


\section{Connotas. Revista de crítica y teoría literarias}

Núm. 13, año 2013

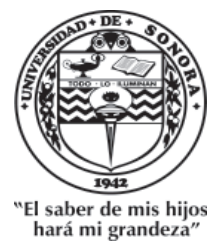


UNIVERSIDAD DE SONORA

RECTOR

Heriberto Grijalva Monteverde

VICERRECTORA

Arminda Guadalupe García de León Peñúñuri

Secretario General Académico

Enrique Fernando Velázquez Contreras

División de Humanidades y Bellas Artes

María Rita Plancarte Martínez

Departamento de Letras y LingÜística

Ana Bertha de la Vara Estrada

César Avilés Icedo

Rosa María Burrola Encinas

Fortino Corral Rodríguez

Leticia Martínez Figueroa

Jesús Abad Navarro Gálvez

Gabriel Osuna Osuna

María Rita Plancarte Martínez

DiRECTOR

Fortino Corral Rodríguez

Giuseppe Bellini

Consejo InTERnacional

Universidad de Milán

Carlos Pacheco

Luis Beltrán Almería

Universidad Simón Bolivar

Universidad de Zaragoza

Rafael Olea Franco

Helena Beristáin

El Colegio de México

Joan Oleza Simó

Universidad Nacional Autónoma de México

Universidad de Valencia

Raúl Bueno-Chávez

Dartmouth College

Julio Ortega

Evodio Escalante

Brown University

Luz Aurora Pimentel

Universidad Autónoma Metropolitana

Universidad Nacional Autónoma de México

Beatriz González-Stephan

Susana Reisz

Rice University

Aníbal González

The City University of New York.

José Carlos Rovira

Universidad de Alicante

Yale University

Aurelio González Pérez

Charles Tatum

El Colegio de México

Yvette Jiménez de Báez

The University of Arizona

Jorge Urrutia

El Colegio de México

Universidad Carlos III de Madrid

Nelson Osorio Tejeda

Universidad de Santiago de Chile

Emil Volek

Arizona State University 


\section{Índice}

\section{Artículos}

Una hermenéutica analógica para la literatura

Mauricio Beuchot Puente

La obra de Jorge Luis Borges durante la década de 1930: estudio de algunos elementos para la conformación de su poética en Discusión (1932)

Daniel Zavala Medina

Metáforas de la locura y la muerte en "Río subterráneo" de Inés Arredondo

Gabriel Osuna Osuna

La alteridad como vector de la construcción del yo: La muerte me da de Cristina Rivera Garza y El Gran Vidrio de Mario Bellatin Véronique Pitois Pallares

Uno soñaba que era rey de Enrique Serna: un espacio de contradicción Claudia Gidi

Una angustia compartida. Análisis de la voz narrativa en Mi hermano Carlos de Jorge López Páez

Jorge Antonio Muñoz Figueroa

De Los perros románticos y otros poemas de Roberto Bolaño Marina Martínez Andrade 
Las novelas del Crack, multiplicidad y superposición de mundos Ramón Alvarado Ruiz

La construcción del “otro" en la Relación de la jornada de Cíbola de Pedro Castañeda de Nájera

Guillermo Martínez Sotelo

Destino e historia en Margarita, está linda la mar de Sergio Ramírez

María Rita Plancarte Martínez

\section{Notas}

Identidad negada y mundo al revés en Santa María del Circo de David Toscana

César Avilés Icedo y María Elena González Borgaro 203

"El buen ejemplo" de Vicente Riva Palacio: la historia de un cuento

Marco Antonio Chavarín González

Organización descriptiva en Catarina de San Juan, princesa de la India y visionaria de Puebla

Silvia Guadalupe Alarcón Sánchez

Genealogías en Todo aqui es polvo de Esther Seligson. Lectura a partir de los epígrafes

Luz Elena Zamudio Rodríguez

\section{Reseñas}

Martha Elena Munguía Zatarain. La risa en la literatura mexicana (apuntes de poética)

Silvia Alicia Manzanilla Sosa 
Véronique Pitois-Pallares. El arte del fragmento: El Gran Vidrio de Mario Bellatin

Julio César Zárate Ramírez 255

Nicolás Kanellos. Hispanic Immigrant Literature: El sueño del retorno Josué Gutiérrez González

Dante Salgado. Brevísima relación de la idea de amor en Occidente Diana Vanessa Geraldo Camacho 271

Mara L. García. Paco Yunque: una mirada crítica Juan Paredes Carbonell 279

Abstracts 283

Résumés

Normas editoriales 



\title{
Genealogías en Todo aqui es polvo de Esther Seligson. Lectura a partir de los epígrafes
}

\author{
LuZ Elena Zamudio RodrígueZ*
}

Todos, seamos nobles o no, tenemos nuestras genealogías. Yo desciendo del Génesis, no por soberbia sino por necesidad. Mis padres nacieron en una Ucrania judía, muy diferente a la de ahora y mucho más diferente aun del México en que nací, este México, Distrito Federal.

Margo Glantz

\section{Resumen:}

El presente trabajo es una aproximación al libro Todo aqui es polvo de Esther Seligson a través de los títulos y los epígrafes. Se parte del planteamiento de Gerard Genette que considera los elementos paratextuales como elementos dialogísticos que movilizan el horizonte de expectativas del lector e inducen un acercamiento hermenéutico al texto, en este caso, un texto de carácter autobiográfico.

\section{Palabras clave:}

Esther Seligson, autobiografía, epígrafes.

A Pilar Nieto y a Geney Beltrán Félix, con agradecimiento. ${ }^{1}$

* UAM-Iztapalapa.

${ }^{1}$ Pilar Nieto fue gran amiga de Esther Seligson y en sus ejemplares hice mis primeras lecturas sobre la escritora que me ha despertado gran interés. A Geney Beltrán Félix, narrador, ensayista y crítico, agradezco sus respuestas, a través de internet, a preguntas como la relación del último epígrafe de la autobiografía, que lleva su nombre. El mencionado epígrafe incluye la frase del título de la autobio- 
La autobiografía escrita por Esther Seligson, ${ }^{2}$ publicada en 2010, año en que murió su autora, está dividida en cuatro partes, de las cuales para esta presentación elegí sólo la primera que considero representante de su genealogía, pues los protagonistas de esta sección de su historia de vida, son sus padres y su hermana Silvia.

Este género de escritura se caracteriza por ser un relato retrospectivo en prosa que una persona hace de su historia y que no puede desligarse del concepto subjetivo de la propia personalidad. El estudio teórico de la autobiografía ha dado motivo a muchas investigaciones que tratan de deslindarla de otros géneros cercanos como la novela, las memorias, y la novela autobiográfica. Sin embargo, es un hecho que se trata de una narración matizada por el autor que reconstruye la historia de su vida, a partir de un proyecto de escritura.

En este trabajo no me acerco al texto directamente, sino solamente a través de la interpretación de dos de los elementos que la enmarcan: los títulos y los epígrafes que pongo a dialogar con la obra.

Gerard Genette en su libro Umbrales considera que: "el paratexto, bajo todas sus formas, es un discurso fundamentalmente heterónomo, auxiliar, al servicio de otra cosa que constituye su razón de ser: el texto" (26). El autor llama la atención sobre la importancia de estos elementos aparentemente con poca trascendencia y cuya presentación ha variado con el tiempo, pero que influyen consciente o inconscientemente en los receptores.

Los paratextos están al borde de la obra como señala Gerard Genette, pero abren expectativas a los lectores y, en ocasiones, como es el caso de la autobiografía de Esther Seligson, definen su estructura e invitan a un acercamiento hermenéutico a partir de la interpretación de los textos que están sugeridos o citados en estos epígrafes, e

grafía. Geney Beltrán Félix fue alumno de Seligson, y ésta, después de recibir la negativa de titular de ese modo una novela de Geney, aún inédita, le pidió esa frase, "todo aquí es polvo", para identificar su autobiografía, lo cual resultó adecuado y sugerente, además de hacer énfasis en la propuesta autobiográfica de la escritora.

${ }^{2}$ Me refiero a Todo aquí es polvo. Obtuvo el Premio Bellas Artes-Colima al mejor libro de narrativa publicado en México en 2010. 
ir moviendo el horizonte de expectativas a medida que se avanza en la lectura y se profundiza en el conocimiento de la obra, pues despierta muchas curiosidades que es difícil no satisfacer en el trayecto de la interpretación del libro.

Los epígrafes aparecen desde el principio; después del título y los agradecimientos se encuentran tres, que abren una gama de posibilidades de lectura. El epígrafe inicial está tomado del Fausto de Goethe y alude a un límite muy particular entre el pasado y el futuro vivido por el protagonista de la obra de procedencia: “¡Ay!, en aquellos tiempos cuánta nostalgia sentí, al ver pasar sobre mí las alas de una grulla, de llegar a la orilla del mar inconmensurable, de beber en la copa de lo infinito aquel gozo de la vida enardeciente y sentir la limitada fuerza de mi pecho, sólo por un instante, una gota de la dicha del ser que crea todo por sí y en sí mismo" (9); enumero a continuación algunos fragmentos del texto citado porque en la autobiografía de Seligson que enmarcan, cambia parcialmente su significado: "nostalgia", "llegar a la orilla del mar inconmesurable", "beber de la copa de lo infinito" y "Sentir en la limitada fuerza de mi pecho, sólo por un instante, una gota de la dicha del Ser que crea todo por sí mismo y en sí mismo"; todas estas palabras en el nuevo contexto probablemente aluden al estado de ánimo de la autora, al momento de su vida en el que decide escribir su historia y a un aparente deseo de reincorporarse al principio y fin de la existencia, cerrar su ciclo vital.

El segundo epígrafe proviene de Los recuerdos del porvenir de Elena Garro, una de las escritoras mexicanas que llamaron la atención de Esther Seligson, quien mostró interés por ella y por su obra; le dio motivos para reflexiones interesantes como las que tiene el ensayo "In illo tempore (Aproximación a la obra de Elena Garro)", incluido en su libro $A$ campo traviesa. Copio el epígrafe completo por su brevedad y por la relación directa que tiene con las escrituras del yo al que pertenece genéricamente el libro que ahora trato: "Yo sólo soy memoria y la memoria que de mí se tenga". En el ensayo antes mencionado, al referirse a Los recuerdos del porvenir dice Seligson en relación con el poder de la memoria: "sólo en el encuentro con el amor el tiempo se hace luz y se suspende, y la palabra coincide con el orden y la alegría originales. Mientras tanto, para desbaratar uno a uno los 
días petrificados, está la intuición de que es posible recuperar la memoria íntegra de ese otro tiempo y de ese otro espacio" (A campo 86).

Del tercer epígrafe se da a conocer sólo el nombre de su autor, Adrián Jorowicz Seligson, segundo hijo de la escritora. Lo transcribo completo y subrayo dos palabras que considero claves porque están presentes en éste y en otros libros de la autora: "La oscuridad es de cualquier color, / sólo la luz es transparente”. Quizá la frase sugiera que cada uno le da a sus oscuridades el color que le inspire, no así la luz cuya claridad es reconocida por todos. Esta misma cita se encuentra entrecomillada en el libro Simiente, escrito por una madre confundida y dolorida frente al mar de Ashkelón. Durante todo el proceso de escritura de Simiente, la autora afirma que vivió algo extraordinario. Así lo dijo en la entrevista que le hizo Angélica Abelleyra en mayo de 2004, publicada en La jornada semanal ese mismo mes, cuando Esther Seligson recién había regresado a México, después de tres años y medio de ausencia, motivada quizá por la muerte de su hijo Adrián.

$\mathrm{Al}$ referirse la escritora a la originalidad y especificidad de su libro comenta:

Simiente es sui generis. [...] para mí es un parteaguas definitivo y por supuesto no habrá otro parecido ni cercano. Lo escribí en un estado de mediumnidad y alucinación de seis semanas. Era como un dictado. [...] con toda la humildad que no tengo, como pudo haber escrito Rimbaud Una estancia en el infierno. ${ }^{3}$ Es algo que no tiene que ver con tu ego ni contigo como persona, en el sentido griego de la palabra y en el sentido jungiano. Tú eres un canal sobre el cual se está vertiendo algo que tiene urgencia de ser expresado. Y que se vierte a

${ }^{3}$ Esther Seligson en $A$ campo traviesa utiliza a Joseph Campbell, quien interpreta la escritura de esta obra de Rimbaud como neurosis creativa y como viaje interior; la manera de explicarla también es aplicable al impulso que llevó a Seligson a escribir Simiente: "La introversión voluntaria, de hecho, es uno de los recursos clásicos del genio creador y puede emplearse como recurso deliberado. Lleva las energías psíquicas a lo profundo y activa el continente perdido de las imágenes infantiles inconscientes y arquetípicas. El resultado por supuesto es una desinte- 
borbotones frente al mar. [...] Es un escrito de tormenta donde no hay pausa pero sí respiración. Y el mar sí se queda callado en algún momento. (Abelleyra)

El contenido de los tres epígrafes presagia un texto autobiográfico, cuyo pacto por parte del lector convierte a este en testigo de los recuerdos que revive en un momento límite su narradora, quien a veces trata de explicarse algunas de las experiencias que le han quedado guardadas en la memoria.

La primera de las cuatro partes del libro autobiográfico Todo aqui es polvo, que yo identifico arbitrariamente con su genealogía, ${ }^{4}$ se titula "Dúo", y está conformada por tres diálogos de la narradora: dos con "Ella", pronombre femenino en tercera persona del singular que representa a las mujeres más trascendentes en su historia personal, su madre y su hermana; y otro con el pronombre "Él", que se refiere a Salomón, su padre.

Después del subtítulo mencionado: Primera parte. Dúo, se presenta al lector un epígrafe algo desconcertante porque es ajeno a la ideología de la autora, está tomado del Nican mopohua, (aqui se narra) un relato náhuatl que cuenta las apariciones de "la madre de los mexicanos" que la reconocen como tal; la Virgen de Guadalupe en el cerro del Tepeyac, cito: “¿No estoy aquí, yo que soy tu Madre?/ ¿No estás aquí bajo mi sombra y resguardo?/ ¿No soy la fuente de tu alegría?/ ¿No estás en el hueco de mi mano, en el cruce de mis brazos?/ ¿'Tienes necesidad de alguna otra cosa?". Esther Seligson no profesaba la fe católica ni sus orígenes fueron mexicanos, sin embargo acerca el nombre de María, madre de Jesucristo, al de Miriam, madre de la narradora, conocida en su ambiente cotidiano como doña Mari y a quien sus hijas llaman "Maña".

gración más o menos completa de la conciencia (neurosis, psicosis; la fuga de la hechizada Dafne), pero por otra parte, si la personalidad es capaz de absorber e integrar las nuevas fuerzas se habrá experimentado un grado casi sobrehumano de autoconciencia y de control dominante" (Campbell 66).

${ }^{4}$ En la segunda parte de Todo aqui es polvo la narradora también recuerda a una de sus abuelas, pero desde una perspectiva distinta. 
Con este epígrafe percibo la intención irónica de la escritora; quien utiliza la semejanza de los nombres de las dos madres a las que se refieren epígrafe y texto, para subrayar el hecho de que ninguna llegó virgen al matrimonio: según la tradición cristiana la Virgen María, cuando se casa con José ya lleva en su seno a Jesús, el hijo de Dios, porque fue preñada, con su consentimiento, por el Espíritu Santo, una de las personas de la Divina Trinidad. En el caso de Miriam, ella le confesó en una ocasión a su hija Esther: "mi propio padre me desvirgaba desde la pubertad" (Todo aqui 50-51). La Virgen María, respondió afirmativamente al ángel mensajero de la divinidad, que pedía su mediación para que su hijo único pudiera hacerse hombre y venir al mundo para ayudar activamente en la salvación de la humanidad. En cambio, en la historia de Miriam se muestra el abuso de un padre que probablemente no respetó la voluntad de su hija; quizá la sedujo, quizá la forzó.

Cada uno de los tres subcapítulos también tiene un epígrafe, el primero "Ella, mi madre" recupera las palabras de uno de los escritores que releyó la autora varias veces: Rainer María Rilke, en Cartas a una amiga veneciana; el epígrafe dice: "Para ser justo con alguien, hay que ver las cosas como si se tratara de morir", 5 esta frase subraya la importancia del aprendizaje de la muerte pues, desde esta perspectiva, es lo que da sentido a la vida. Para el poeta nacido en Praga, la muerte debería ser feliz y entusiasta. Esther Seligson con la voz de su narradora reconstruye los últimos ciento veinte días que vivió Miriam, durante los cuales se preparó para morir. Subraya la narradora que durante ese tiempo su madre se desprendió paulatinamente de sus ataduras terrenales y, con la complicidad de sus hijas, logró un final feliz: "Tal vez se fue entregando a la conciencia de ser ella misma para poder ir hacia ese oleaje más vasto que el dolor de su cuerpo consumido" (Todo 24). ${ }^{6}$

${ }^{5}$ Traducción de Jorge Herrera, directa de Todo aqui es polvo de Esther Seligson.

${ }^{6}$ Esther Seligson en el ensayo "Rilke y la transfiguración de lo visible" de $A$ campo traviesa, p. 23, interpreta que para Rilke: "El hombre debe entregarse a merced de la 
El momento de la muerte de Maña está descrito de manera simbólica, relacionándolo con el oficio de relojero de su marido. El transcurrir del tiempo lineal marcado con el tic-tac que repite su ciclo cada doce horas, en algún momento deja de escucharse y coincide, para la narradora, con el fin de la vida de su madre:

Yo escuché sin el menor lugar a dudas cómo el mecanismo de su corazón fue haciendo cada vez más pausados los golpes de sístole y diástole cual péndulo de reloj-imagen que viene muy a punto dado que mi padre era relojero y, en ese momento, en otra habitación de la casa, totalmente ajeno- hasta que se detuvo el vaivén con un simple "trac" claro, preciso, seco. (Todo 25)

"Ella, mi hermana" se titula el segundo subcapítulo cuyo epígrafe, "también todos parecían construirse alrededor de algo olvidado" (27), está tomado de La ciudad sitiada de Clarice Lispector, escritora nacida en Ucrania que vivió en Brasil la mayor parte de su vida y coincide con Seligson en su origen judío. Tanto Lucrecia, protagonista de la obra mencionada de Lispector, como el yo que cuenta fragmentos de su historia de vida, necesitan encontrar su identidad para ser felices, esto implica separarse de lo que represente un obstáculo para lograr su objetivo. ${ }^{7}$ Sin embargo, le duele a la narradora mexicana separarse de Silvia su hermana y su rival en muchos momentos de su convivencia.

eterna corriente de la vida y la muerte, pues entregándose sin reservas a ella, perdiendo en ella su propio ser, se sentirá integrado en algo superior exento de la opresión de la temporalidad". Esta afirmación es compatible con lo expresado en el epígrafe y con el contenido del texto sobre la muerte de la madre de la narradora.

${ }^{7}$ Seligson en uno de los ensayos sobre sobre esta escritora, titulado "Clarice Lispector: el aprendizaje de la vida", también publicado en $A$ campo traviesa (68-73), tiene un epígrafe tomado del Talmud que hace responsables a los hombres de su propia felicidad. Una de las sentencias dice: "el que se inflige dolor por la abstinencia de algo que desea se llama pecador". Pareciera que desde el punto de vista de Seligson, ambas escritoras están obligadas a encontrar la felicidad por sí mismas, ya que el impulso para lograrlo es intrínseco al ser humano, pero no todos se arriesgan. 
Esther Seligson recurre a E.M. Cioran, otro de sus grandes maestros y amigos a quien trata de entender y describir para aclarar sus confusiones: "no es un filósofo, sin embargo, porque está en contra de cualquier sistema, estructuración o esquematización. Es, simple y complicadamente, un demiurgo" (Apuntes 15). Cioran, a partir de su conocimiento de las relaciones humanas, consideraba frecuente la competencia entre hijos de los mismos padres y, por experiencia propia le resulta comprensible, por lo repetitivo: "la feroz e insalvable rivalidad fraterna" (111). Recuerda que están registrados muchos ejemplos tanto en la historia de la humanidad como en mitologías de distinto origen. Para hacer hincapié en esto, la narradora cita como ejemplos: a Caín y Abel, Jacob y Esaú, Antígona e Ismene y Raquel y Lea. Entre estas parejas ampliamente conocidas ha imperado la intriga y la oscuridad; sin embargo, el yo narrador no se resigna a perder para siempre a su hermana Silvia y aspira a compartir de nuevo algo de la luz que le permitiera reconocerse en ella: "Tal vez quieras, hermana, en alguna otra oportunidad, compartir la luz del último atardecer que vimos frente al mar y te hizo bajar los párpados para encerrarte hermética, de nuevo, tan adentro, tan lejos, solitaria..."(Todo 35).

"El, mi padre" es el subcapítulo con que se cierra esta primera parte del relato que, por los títulos, pone al lector en contacto con tres de los protagonistas de la familia de origen de la narradora, de ahí mi idea de identificarla con sus "genealogías". Ahora se trata de mostrar la figura de Salomón, pero mezclada con reflexiones teóricas sobre la imprecisión de la memoria, ejercicio metaficcional al que está recurriendo la autora para reelaborar su vida pasada. El epígrafe, que tiene su origen en un aforismo tántrico: “Lo que está aquí está allá. Lo que está aquí no está en ninguna parte”, alude al difícil proceso que vivió Salomón para lograr la armonía al final de su vida y conseguir que lo que esté arriba sea igual a lo que está abajo, para realizar los milagros de una única cosa, como lo sugiere la Tabla esmeraldina. El padre de la narradora recorre un camino difícil al reconstruir su propia historia que incluye una cadena de indiferencias que lo marcó a él y a toda su descendencia, pues, al parecer no escogió su destino, sino que: "le cayó literalmente del cielo como a cual- 
quier personaje de tragedia griega y sin Oráculo de por medio" (38). Toda esta adversidad propició su ambigüedad ante la pertenencia y el amor. No obstante eso, al final de su vida Salomón logra el descanso eterno cuando se decide a soltar su amargura, propiciada por las marcas del exilio que limitaron sus posibilidades de desarrollo profesional y personal. Transcurridos ochenta días de soledad, se libera de su entorno y puede morir en paz; al parecer logró encontrarse consigo mismo.

Esta es la imagen que interpreto de la historia de la relación que el yo narrador establece con sus padres y su hermana, y termino con la referencia que Esther Seligson hace al sabio y estudioso del Talmud, Adin Steinsaltz, porque creo que abarca la valoración que la propia autora hace de la veracidad de sus dichos: "toda luz tiene su sombra, y la sombra su propia sombra. Tal vez sólo lo que nos empeñamos en 'eternizar' (¿idealizar?) es lo que sobrevive, el resto es únicamente despojo" (58).

Con la misma propuesta de lectura a partir de títulos y epígrafes tengo avanzada la interpretación de las otras tres partes de Todo aquí es polvo; dejamos esta tarea para futuros trabajos.

\section{Bibliografía}

Abelleyra, Angélica (entrevistadora). "Simiente, un escrito de tormenta”. La jornada semanal (suplemento cultural de La jornada), núm. 478, 2 de mayo de 2004.

Campbell, Joseph. El héroe de las mil caras. México: FCE, 1959.

Genette, Gérard. Umbrales. Tr. Susana Lage. México: Siglo XXI, México, 2001.

Goethe, Johann W. Fausto. Citado en Seligson, Todo aqui es polvo. México: Broguera, 2010.

"Nican Mopohua. (Texto original de las apariciones de la virgen de Guadalupe a san Juan Diego)". Consultado en <www.mariaamada. org/rincon/nican.pdf $>$ el 24 de febrero de 2014.

Seligson, Esther. Todo aqui es polvo. México: Bruguera, 2010.

- A campo traviesa. México: FCE, 2005.

- Apuntes sobre E. M. Cioran. México: Conaculta, 2003. 